\title{
Динамика российских изобретений
}

\section{П. Мазуркин,}

д-р техн. наук, профессор, федеральный эксперт РИнКЦЭ, заведующий кафедрой природообустройства Поволжского государственного технологического университета (г. Йошкар-Ола)

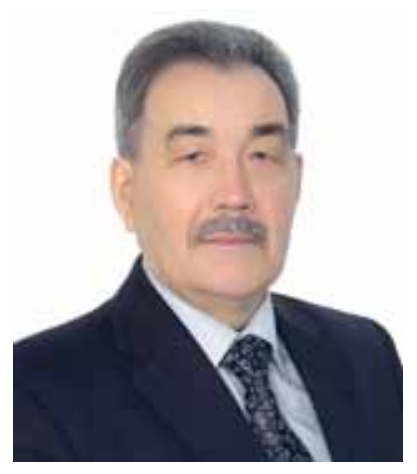

В статье дан анализ статистических моделей динамики ежегодной численности российских патентов на изобретения, а также других объектов промышленной собственности (ОПС) с 2006-го по 2012 гт. При этом полезные модели, промышленные образцы, товарные знаки и знаки обслуживания объединены в группу «не статусные по мировой новизне ОПС». Показаны новые критерии для научнотехнологического мониторинга по видам ОПС.

\section{Ключевые слова:}

изобретения, объекты промышленной Keywords:

собственности, динамика, статистические модели, поведение российских изобретателей.

Совершенствование организации и повышение качества государственной научно-технической экспертизы изобретений, промышленных образцов, полезных моделей, товарных знаков и других объектов интеллектуальной собственности далее невозможно без статистического (вероятностного) моделирования динамики отечественных изобретений и других видов объектов промышленной собственности (далее - ОПС).

Создание и развитие единой государственной системы учета этих результатов пока остается 
только на уровне самих ОПС: изобретатели в официальном анализе изобретательской активности в регионах России [1] вообще не упоминаются. Тем не менее новые научно-технические решения создают не государственные корпорации, не предприятия и фирмы, а вполне конкретные изобретающие личности.

Именно изобретения, а не полезные модели и другие виды ОПС, определяют уровень мировой новизны будущих отечественных разработок, а сравнение банков изобретений с зарубежными странами и корпорациями дает возможность оценки конкурентоспособности российской технологической базы экономики и отдельных государственных корпораций. Комплекты изобретений дают также возможность защиты продукции для выхода на экспорт.

Можно привести наглядный пример: по сообщениям в прессе, все российские государственные корпорации за год получили около 1000 изобретений, а компания IBM одна за год получила на свою продукцию более 5000 патентов. Проблема в нашей стране в том, что чиновникам и элите бизнеса нужны не сами изобретения, а только сиюминутная прибыль.

Ниже представлен анализ динамики изобретений и других видов ОПС согласно приведенным данным [1].
Данные о подаче в Роспатент заявок на объекты промышленной собственности (ОПС) приведены в таблице 1. Российские изобретения имеют мировую новизну (по правилам ФИПС), но разную конкурентоспособность.

А полезные модели, как и другие виды ОПС, нужны В основном для внутреннего употребления. Поэтому их численность, как и других видов не статусных ОПС, изменяется по другим законам, чем количество изобретений. В итоге образуется противоречивый так называемый инновационный крест.

С трендом в виде закона экспоненциального роста и волновой составляющей изменяется численность заявок на изобретения (рис. 1). Коэффициент корреляции (мера тесноты факторной связи по уровням) для тенденции равен 0,8035 (сильная связь), для волны 0,9326 (сильнейшая связь).

Для сравнения по данным табл. 1 получили уравнение динамики количества заявок на изобретения $N_{\dot{E}}$ как важнейшего параметра инновационной системы (табл. 1, рис. 1):

$$
\begin{aligned}
& N_{?}=37950,58 \exp \left(0,030241 t^{0,81741}\right)+ \\
& 1697,5302 t^{5,06325} \exp (-1,78390 t) \cos (\pi t),
\end{aligned}
$$

где постоянный период колебательного возмущения равен двум годам.

\begin{tabular}{|c|c|c|c|c|c|c|c|c|}
\hline \multirow{3}{*}{ Год } & \multirow{3}{*}{$\begin{array}{c}\text { Время } \\
t, \text { лет }\end{array}$} & \multicolumn{5}{|c|}{ Вид объекта промышленной собственности } & \multirow{3}{*}{$\begin{array}{c}\text { Всего } \\
\text { опс }\end{array}$} & \multirow{3}{*}{$\begin{array}{c}\text { Доля } \\
\text { изобретений } \\
\alpha, \%\end{array}$} \\
\hline & & \multirow[b]{2}{*}{$\begin{array}{c}\text { изобрете- } \\
\text { ние }\end{array}$} & \multicolumn{4}{|c|}{ не статусные по мировой новизне ОПС } & & \\
\hline & & & $\begin{array}{c}\text { полезная } \\
\text { модель }\end{array}$ & $\begin{array}{c}\text { промыш- } \\
\text { ленный } \\
\text { образец }\end{array}$ & $\begin{array}{c}\text { товарный } \\
\text { знак и знак } \\
\text { обслужива- } \\
\text { ния }\end{array}$ & Итого & & \\
\hline 2006 & 0 & 37691 & 9699 & 4385 & 52984 & 67068 & 104759 & 35,98 \\
\hline 2007 & 1 & 39439 & 10075 & 4823 & 57262 & 72160 & 111599 & 35,34 \\
\hline 2008 & 2 & 41849 & 10995 & 4711 & 57112 & 72818 & 114667 & 36,50 \\
\hline 2009 & 3 & 38564 & 11153 & 3740 & 50107 & 65000 & 103564 & 37,24 \\
\hline 2010 & 4 & 42500 & 12262 & 3997 & 56848 & 73107 & 115607 & 36,76 \\
\hline 2011 & 5 & 41414 & 13241 & 4197 & 59717 & 77155 & 118569 & 34,93 \\
\hline 2012 & 6 & 44211 & 14069 & 4640 & 61923 & 80632 & 124843 & 35,41 \\
\hline
\end{tabular}

Динамика подачи заявок в России на объекты промышленной собственности (ОПС) 
Как видно, 2012 г. стал переломным: амплитуда колебания $A=2$ x $\left(1697,5302 t^{5,06325} \exp (-1,78390 t)\right)$ через несколько лет придет к нулю. Но скорее всего «показатель волнения» изобретателей по количеству заявок ( \pm 800 шт.) будет постоянным.

Количество заявок на полезные модели $N_{\eta}$ за 20062012 гг. меняется по простой формуле полного закона экспоненциального роста:

$$
N_{i l}=9699,9269 \exp \left(0,044681 t^{1,18790}\right) .
$$

Колебание малое, что связано с простотой оформления заявки и в 4-10 раз меньшими сроками получения патента. По сути, это то же самое, что рационализаторское предложение в советское время.
Количество заявок на промышленные образцы $N_{\text {in }}$ изменяется в соответствии с графиками на рис. 1 по формуле:

$$
\begin{aligned}
& N_{n}=4672,5788 \exp (0,0052262 t)- \\
& -34,96865 t^{11,69758} \exp (-3,23118 t)- \\
& -A \cos (\pi t / p+0,29561), \\
& A=259,20561 \exp (-0,040116 t), \\
& p=1,76915-0,067291 t,
\end{aligned}
$$

где A - амплитуда (половина) колебательного возмущения, $p$ - полупериод колебания (частота колебания будет равна $1 / p)$.

Первая составляющая (см. формулу (3) является законом экспоненциального роста (закон Лапласа в математике, Мандельброта в физике, Ципфа
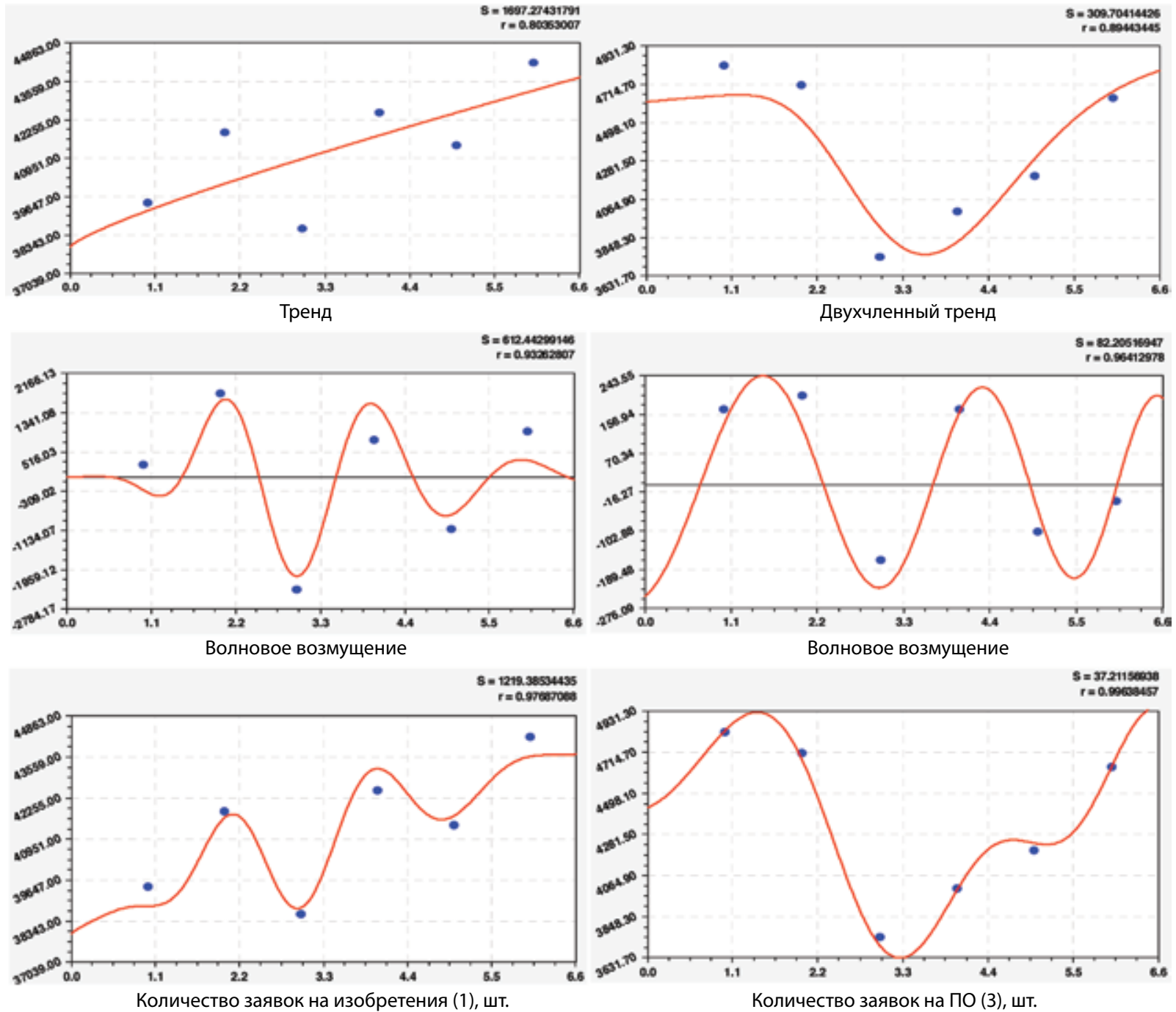
в биологии и Парето в экономике). А вторая показывает кризисное (отрицательный знак пред членом) изменение показателя. Двухчленный тренд на рис. 4 имеет минимум в 2009 г.

Таким образом, можно сделать вывод о том, что на количество заявок на промышленные образцы в России активное влияние оказал мировой кризис. Спад произошел в 2007-2009 годах, а медленное возвращение к значению 2007 г. произойдет только к 2015 г.

Кризисное колебание имеет бесконечномерный характер. По амплитуде она медленно уменьшается давно. Но опасность для инновационной системы России представляет снижение периода колебания от 2 x 1,76915 3,5 года в 2006 г. до 2,7 лет в 2012 г. и далее произойдет учащение до 1,7 года в 2020 г.

Если не принять кардинальных мер, то частота колебания возрастет до полной неуправляемости системой.

Подача заявок на товарные знаки и знаки обслуживания $N_{\text {ос }}$ (рис. 2) идет по двухчленной закономерности

$$
\begin{aligned}
& N_{\text {oఢ }}=52995,58 \exp \left(0,076514 t^{0,36435}\right)- \\
& -792318,3 t^{29,93680} \exp \left(-15,59650 t^{0,79464}\right) .
\end{aligned}
$$

С коэффициентом корреляции 0,9949 (сверхсильная связь) формула (4) показывает сильное влияние мирового кризиса на численность товарных знаков
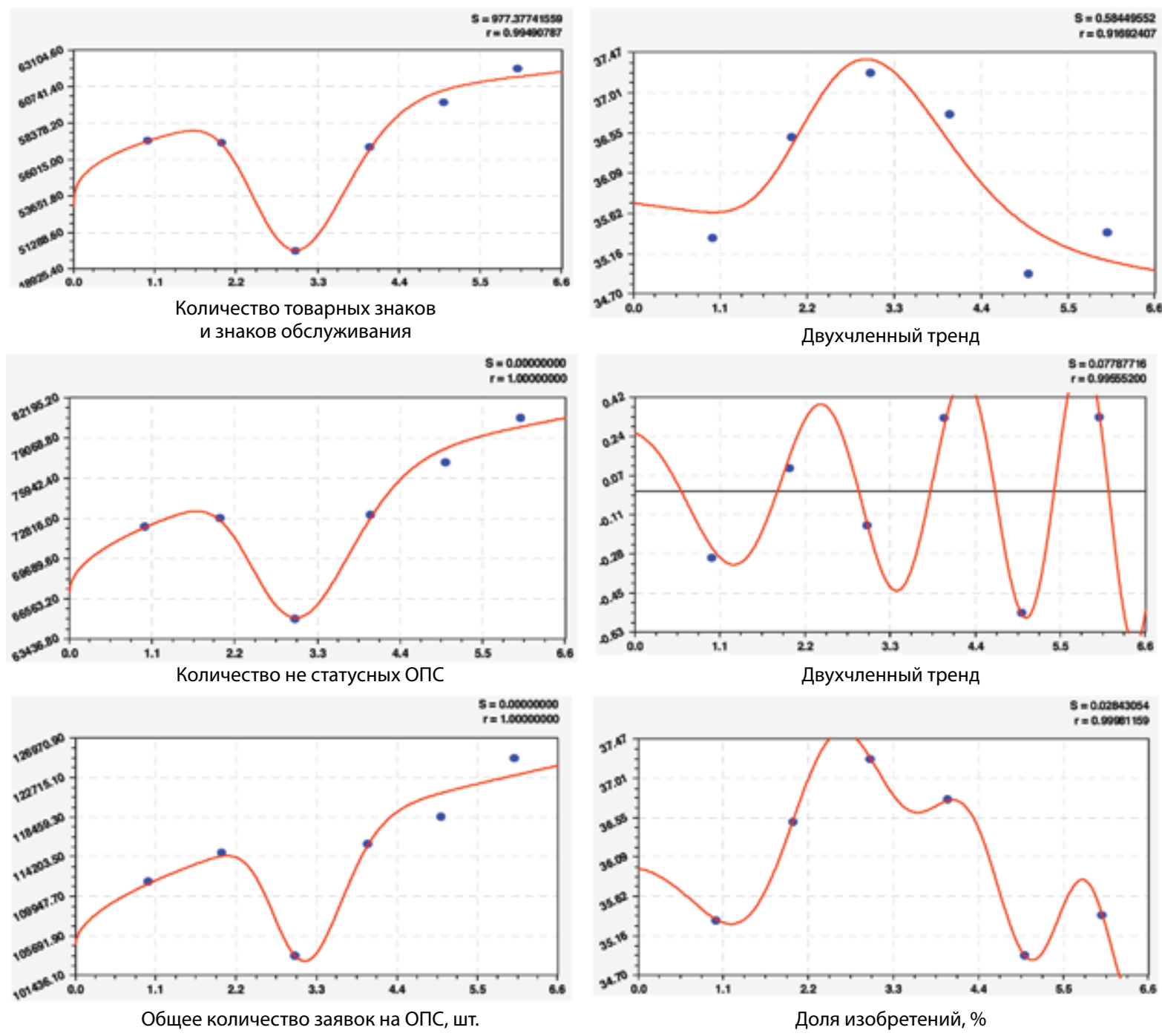

Рис. 2. Динамика не статусных заявок и доли изобретений в России в 2006-2012 г2. 
и знаков обслуживания. Таким образом, количество заявок на изобретения и полезные модели мало зависит от мировой конъюнктуры и по сути является только внутренним делом России.

Динамика не статусных по мировой новизне ОПС $N_{\text {IN }}$ (рис. 2) изменяется по формуле:

$$
\begin{aligned}
& N_{\text {IN }}=67095,55 \exp \left(0,072027 t^{0,49601}\right)- \\
& -1,18012 \cdot 10 t^{29,93680} \exp \left(-20,58554 t^{0,71064}\right) .
\end{aligned}
$$

Преобладает количество заявок на промышленные образцы и товарные знаки.

Влияние количества заявок на изобретения и полезные модели (рис. 2) малое, и поэтому по общему количеству ОПС $N_{\text {थाN }}$ получилась модель:

$$
\begin{aligned}
& N_{\pi / N}=104872,13 \exp \left(0,059788 t^{0,54652}\right)- \\
& -3,36176 \cdot 10^{7} t^{60,16922} \exp \left(-31,36274 t^{0,78056}\right) .
\end{aligned}
$$

Как видно из остатков формулы (6), происходит наращивание новой волны возмущения значений $\mathrm{N}_{\text {IіN }}$ с 2011 г. Ее влияние можно оценить по новым данным 2013 г. Дополняя таблицу 1 новыми данными и пересматривая статистические модели, можно проводить ежегодный мониторинг инновационной деятельности, в том числе и по субъектам федерации.

\section{Число патентов на полезные модели поддерживается с достаточным ежегодным приростом, а в отношении изобретений технология выдачи патентов с советских времен не изменилась}

По данным таблицы 1, для доли изобретений $a=N_{\dot{E}} / N_{\text {IіN }}$ из общего количества заявок была получена модель вида (рис. 1):

$$
\begin{aligned}
& a=35,69084 \exp (-0,0029681 t)+ \\
& +0,68727 t^{11,41052} \exp (-3,82061 t)+ \\
& +A \cos (\pi t / p+0,28056), \\
& A=0,27283 \exp (0,14891 t), \\
& p=1,84814-0,40203 t .
\end{aligned}
$$

Доля изобретений показывает качество ОПС с точки способности российской инновационной системы. Этот показатель является основным в общей оценке страны в мире и отдельных регионов внутри России.

Как видно из конструкции формулы (7), все члены модели позитивные, т.е. стрессовое возбуждение изобретателей (вторая составляющая) и волновое возмущение имеют положительный знак. Таким образом, естественный тренд - это гибель российского изобретательства и замещение его результатов второстепенными (не статусными) ОПС. Волновое возмущение изобретателей происходит по повышающейся амплитуде и частоте колебания. Этот процесс можно сравнить с нарастанием аварийной ситуации в двигателе внутреннего сгорания, когда он идет «в разнос». При превышении некоторого уровня амплитуды (более 60-70\% от тренда) и частоты колебания (период менее года) еще не зародившаяся инновационная система России просто лопнет - как двигатель, который после аварии перестанет работать. Расчеты по формуле (7) показали, что с 2010 г. наша страна уже вошла в аварийное состояние по частоте колебательного возмущения.

Далее рассмотрим (табл. 2) динамику выдачи разных видов патентов российским новаторам.

Результативность работы российских изобретателей и экспертов ФИПС можно оценивать по показателям, приведенным в таблице 2. Отдельно рассмотрим коэффициенты полезного действия (далее - КПД) российских изобретателей. Сопоставлением российских и зарубежных изобретений можно выявить и коэффициенты конкурентоспособности первых из них.

Количество фактически выданных ФИПС патентов на изобретения $N_{O \dot{E}}$ (рис. 3) определяется трехчленной моделью:

$$
\begin{aligned}
& N_{O E}=18559,25 \exp (0,025063 t)+ \\
& +25,83091 t^{11,13766} \exp \left(-0,79350 t^{1,94833}\right)+ \\
& +A \cos (\pi t / p+0,73409) \\
& A=441,43544 \exp (0,095674 t) \\
& p=1,84814-0,00011252 t^{4,18942} .
\end{aligned}
$$

Первая составляющая, в виде естественного тренда по закону экспоненциального роста, показывает поведение системы «изобретатели - ФИПС». Вторая антропогенная составляющая, как и при количестве 
Динамика выдачи патентов РФ российским новаторам

\begin{tabular}{|c|c|c|c|c|c|}
\hline \multirow[b]{2}{*}{ Год } & \multirow{2}{*}{$\begin{array}{c}\text { Время } \\
t, \text { лет }\end{array}$} & \multicolumn{2}{|c|}{ Вид ОПС } & \multicolumn{2}{|c|}{ КПД россиян } \\
\hline & & изобретение $N_{O \hat{O E}}$ & полезная модель $N_{\text {о̆іi }}$ & $\begin{array}{c}\text { изобретение } \\
\eta_{\dot{E}}=N_{\hat{O} \dot{E}} / N_{\dot{E}}\end{array}$ & $\begin{array}{c}\text { полезная модель } \\
\eta_{\dot{E}}=N_{\text {ӧil }} / N_{i j}\end{array}$ \\
\hline 2006 & 0 & 19138 & 9195 & 0,5078 & 0,9480 \\
\hline 2007 & 1 & 18431 & 9311 & 0,4673 & 0,9242 \\
\hline 2008 & 2 & 22260 & 9250 & 0,5319 & 0,8413 \\
\hline 2009 & 3 & 26294 & 10500 & 0,6818 & 0,9415 \\
\hline 2010 & 4 & 21627 & 10187 & 0,5089 & 0,8308 \\
\hline 2011 & 5 & 20339 & 10571 & 0,4911 & 0,7984 \\
\hline 2012 & 6 & 22481 & 11152 & 0,5085 & 0,7927 \\
\hline
\end{tabular}

заявок, дает картину противодействия творческой части населения кризису. Третья волновая составляющая находится в зависимости от пертурбаций в так называемой элите, или же надстройке общества: снова амплитуда колебания нарастает, а полупериод убывает (частота повышается), и вся система идет «вразнос».

Иной характер поведения имеет изменение количества фактической выдачи патентов $N_{\text {оіi }}$ на полезные модели (рис. 3) по трехчленной формуле:

$$
\begin{aligned}
& N_{\text {Öil }}=9190,65 \exp (-0,11954 t)+ \\
& +1182,2243 t^{1,21539} \exp (-0,077302 t)+ \\
& +A \cos (\pi t / p-2,08378), \\
& A=465,64954 t^{2,70612} \exp (-0,97810 t), \\
& p=0,92877-0,068911 t .
\end{aligned}
$$

Первый член формулы (9) является законом экспоненциальной гибели и показывает естественное стремление изобретателей России к снижению подачи не статусных заявок. Видимый рост происходит за счет второй составляющей, т.е. за счет антропогенного воздействия от ФИПС, оперативно выдающего патенты на полезные модели. Если в 3-5 раз быстрее рассматривать заявки на изобретения, то доля изобретений повысится, в особенности от студентов и учащейся молодежи. Волна по амплитуде убывает, а по частоте - успокаивается.

Таким образом, число патентов на полезные модели поддерживается ФИПС с достаточными темпами ежегодного роста, а в отношении изобретений технология выдачи патентов с советских времен не изменилась.

Коэффициенты полезного действия изобретателей и рационализаторов нашей страны изменяются (рис. 4) по формулам:

КПД $\eta_{\dot{E}}$ получения патентов на изобретения

$$
\begin{aligned}
& \eta_{\dot{E}}=0,48784 \exp (0,0038983 t)+ \\
& +0,11958 \mathrm{t}^{35,43713} \exp \left(-12,82365 t^{1,00017}\right) .
\end{aligned}
$$

Коэффициент полезного действия $\eta_{i l}$ выдачи патентов на полезные модели изменяется по формуле:

$$
\begin{aligned}
& \eta_{i l l}=0,94514 \exp (-0,00048303 t)- \\
& -0,022158 t^{1,09110}+A \cos (\pi t / p-1,42366), \\
& A=0,094169 t^{5,22745} \exp (-1,99123 t) \\
& p=1,12336+0,048554 t
\end{aligned}
$$

Количество патентов на изобретения снизилось в кризисные годы, а количество патентов на полезные модели - изменялось волнообразно. В итоге общая инновационная активность россиян стремительно падает по мировому уровню новизны.

Как следует из долгосрочного прогноза научнотехнологического развития Российской Федерации (до 2025 г.) [2] (далее - Прогноз), восприимчивость российского бизнеса к нововведениям остается низкой. В 2007 г. разработку и внедрение технологических инноваций выполняли 9,4\% от общего числа 

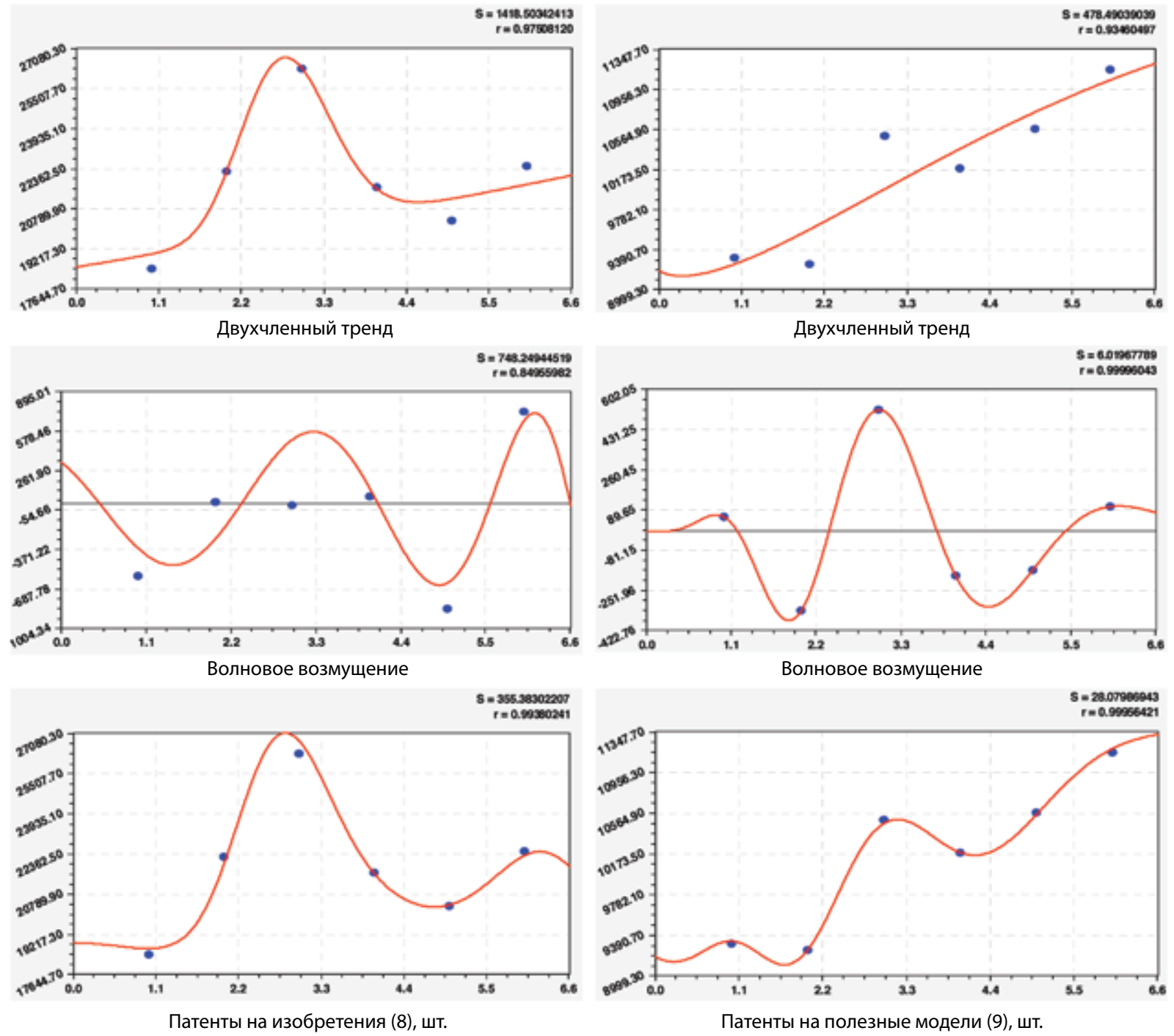

Рис. 3. Количество выданных патентов на изобретения и полезные модели
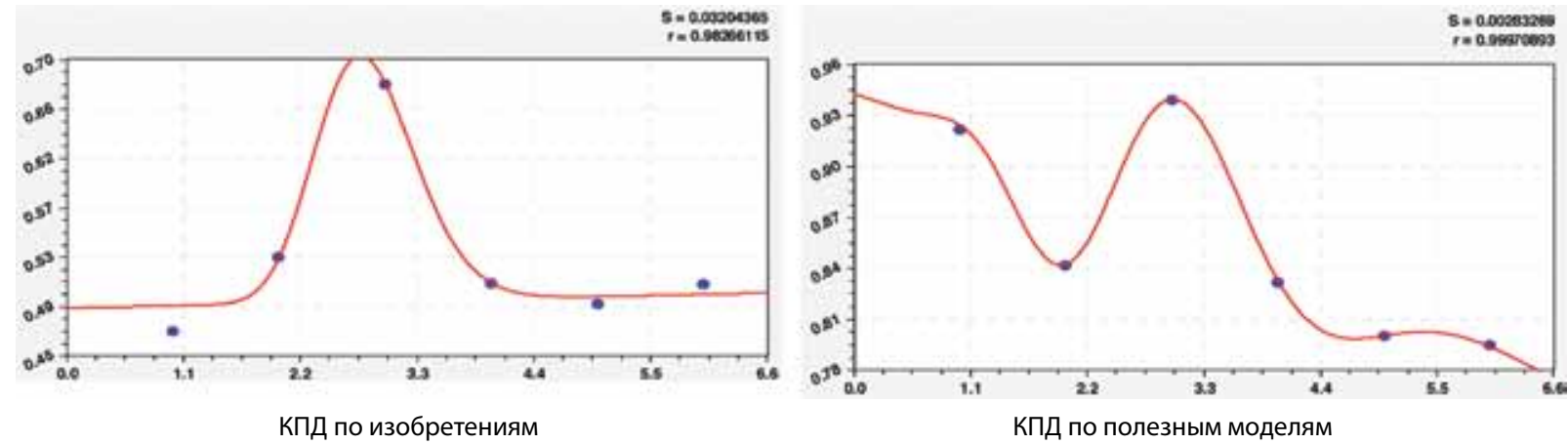

Puс. 4. Динамика коэффициента полезного действия изобретателей России

предприятий, что значительно ниже, чем в Германии (73\%), Ирландии (61\%), Бельгии (58\%), Эстонии (47\%), Чехии (41\%). Хотя изобретательская актив- явок на 1 млн населения) ниже, чем в других развитых странах (в 3-4 раза - по сравнению с Германией и США, в 18 раз ниже, чем в Японии). 
Более 70\% российских изобретений направлено на поддержание и незначительное усовершенствование действующей техники и технологий. Как и в советское время, патентоспособные технические решения обладают очень малым генотипическим расстоянием от прототипов. Внедрение таких изобретений не дает предприятиям длительного экономического эффекта. Отсутствие патентной охраны не дает развиться экспорту.

К сожалению, в Прогнозе нет ни слова о самом инноваторе - живом изобретателе и рационализаторе. Вся инновационная система понимается как некая организационная структура, причем без творчески активных личностей. Поэтому нет никаких стимулов, хотя бы в виде авторского вознаграждения за изобретение, как это было в советское время.

В заключение можно отметить, что принятый закон [3] в некоторой степени доводит нормативно-правовое обеспечение изобретательской деятельности

\section{ЛИТЕРАТУРА:}

1. Анализ изобретательской активности в регионах // analiz_inv_act_2012.pdf.

2. Концепция долгосрочного прогноза научно-технологического развития Российской Федерации на период до 2025 г. - Минобрнауки РФ. - М., 2006.

3. Федеральный закон Российской Федерации от 23 июля 2013 г. № 222-Ф3 «О внесении изменений в часть четвертую Гражданского кодекса Российской Федерации» - Российская газета, 25 июля 2013 г. до уровня советских времен. По этому закону должны вводиться порядок и сроки выплаты вознаграждения за служебные изобретения, служебные полезные модели, служебные промышленные образцы.

\section{Более 70\% российских изобретений направлено на поддержание и незна- чительное усовершенствование действующей техники и технологий}

Однако снова и снова конкретные изобретатели как творческие личности остаются в стороне - ведь они служебные, а значит, остаются крепостными у чиновников. За более чем сто лет ни один крупный изобретатель в царской России, а затем в СССР и в современной России, не стал крупным промышленником, таким как Эдисон или Гейтс в США. 